\title{
БИОТОПИЧЕСКОЕ РАСПРЕДЕЛЕНИЕ ПРЯМОКРЫЛЫХ НАСЕКОМЫХ (ORTHOРТЕRА) НЕКОТОРЫХ ОКРЕСТНОСТЕЙ СЕЛА ИЛЬИНКА
}

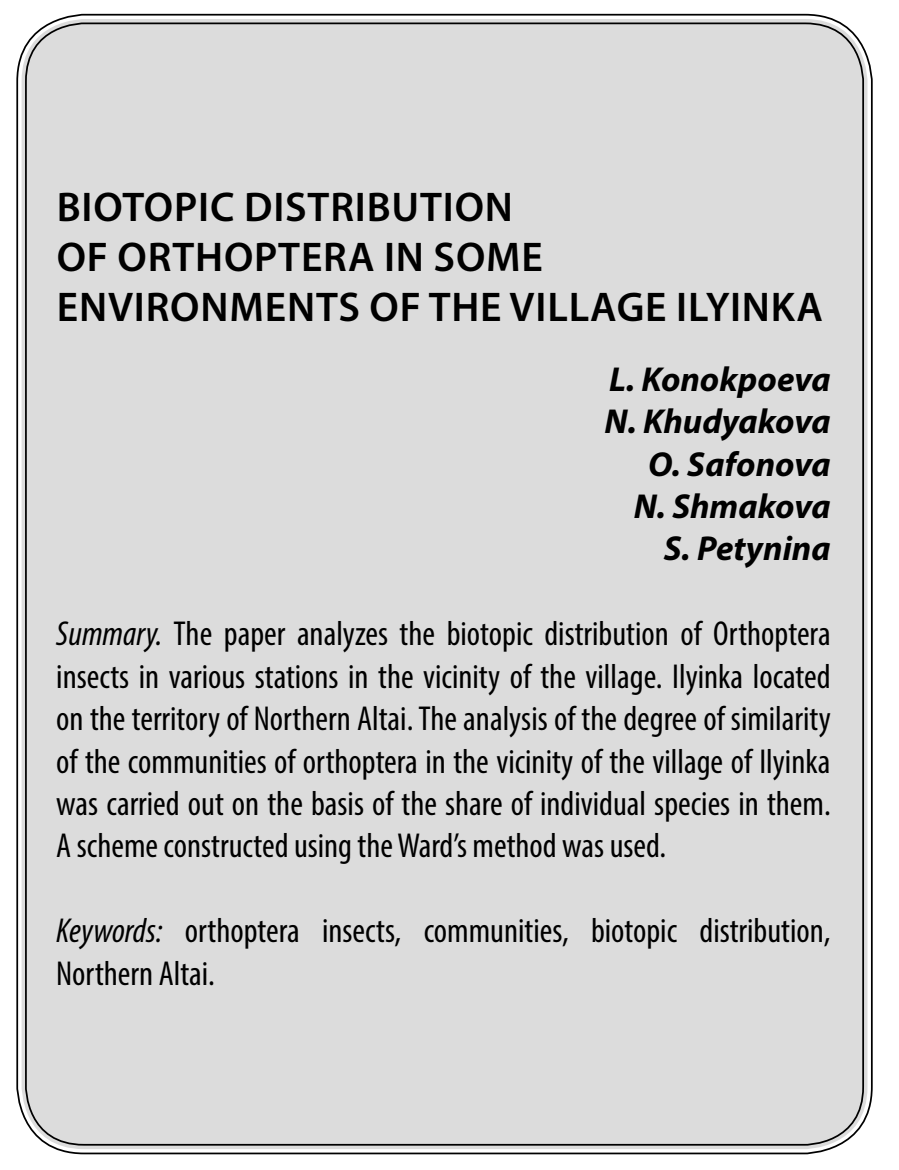

\section{Введение}

$\Pi$ рямокрылые насекомые, к которым относятся кузнечики и саранчовые являются важным звеном природных экосистем. Они не только являются консументами пищевых цепей, но и играют важную роль в почвообразовании, особенно в засушливых районах. В связи с тем, что многие из них являются опасными многоядными вредителями сельхозугодий (пастбищ, посевов, сенокосов, пашен) это в свою очередь оказывает колоссальный экономический урон. Вместе с тем, биологические особенности этих насекомых, их широкая распространенность и тесная связь с травянистыми ландшафтами, которые они населяют, все больше привлекают внимание ученых.

С каждым годом для исследователей все более популярнее становится тема установления закономерностей пространственного распределения сообществ прямокрылых насекомых, в первую очередь это связано с об-
Конокпоева Любовь Александровна

Горно-Алтайский государственный университет

konokpoeva92@gmail.com

Худякова Надежда Ефремовна

К.б.н., дочент, Горно-Алтайский государственный университет

Nch752@bk.ru

Сафонова Оксана Владимировна

К.с.-Х.н., доцент, Горно-Алтайский государственный университет

oksvarias@mail.ru

Шмакова Наталья Юрьевна

Горно-Алтайский государственный университет

Nataliashmakova1998@gmail.com

Петунина Светлана Сергеевна

Горно-Алтайский государственный университет petunina-sveta@mail.ru

Аннотация. В работе проанализировано биотопическое распределение прямокрылых насекомых в различных стациях окрестностей с. Ильинка расположенного на территории Северного Алтая. Анализ степени сходства сообществ прямокрылых окрестностей села Ильинка проводился на основе долевого участия в них отдельных видов. Была использована схема, построенная с помощью метода Варда.

Ключевые слова: прямокрылые насекомые, сообщества, биотопическое распределение, Северный Алтай.

щим физико-географическим размежеванием территорий или же из-за изменения структуры растительного покрова.

Выявление закономерностей пространственного распределения является первоочередным для регионов глобального освоения, так как понятно, что изменение характера антропогенного воздействия приводят к значительным перегруппировкам сообществ Orthoptera [1, 2, 3].

Фауна, биотопическое распределение и особенности сезонной динамики группировок прямокрылых насекомых на территории Северного Алтая изучены довольно хорошо $[4,5]$. Для этого же региона предпринята попытка использовать эту группу для индикации туристко-рекреационного воздействия на экосистемы [6]. Вместе с тем все еще остается актуальным изучение биотопического распределения сообществ прямокрылых насекомых в условиях горных экосистем, в незначительной степени подвергающихся антропогенному воздействию. 
Таблица 1. Видовой состав и обилие группировок прямокрылых насекомых окрестностей с. Ильинка

\begin{tabular}{|c|c|c|c|c|c|c|c|c|c|c|}
\hline \multirow{2}{*}{ Виды } & \multicolumn{10}{|c|}{ Сообщества } \\
\hline & 1 & 2 & 3 & 4 & 5 & 6 & 7 & 8 & 9 & 10 \\
\hline Metrioptera brachyptera (L.) & - & - & - & - & - & 2 & - & - & 2 & - \\
\hline Bicolorana bicolor (Uv.) & 2 & 2 & - & - & - & - & - & - & - & - \\
\hline Isophya altaica B.-Bien. & - & 2 & - & - & - & - & - & - & - & - \\
\hline Conocephalus dorsalis (Latr.) & - & 2 & - & 2 & - & 2 & - & 2 & - & - \\
\hline Tessellana vittata (Charp.) & - & - & - & - & - & 2 & - & - & - & - \\
\hline Roeseliana roeselii (Hagen.) & - & - & - & - & 4 & - & - & - & - & - \\
\hline Gomphocerus rufus (L.) & - & - & - & - & 2 & - & 4 & - & - & - \\
\hline Glyptobothrus biguttulus (L.) & 12 & - & 12 & 30 & - & 54 & 20 & 24 & 46 & 16 \\
\hline Chorthippus apricarius (L.) & 10 & 12 & 6 & 20 & 6 & 10 & 12 & 28 & 16 & 30 \\
\hline Chorthippus fallax (Zub.) & - & 2 & - & 12 & - & 8 & 10 & 6 & 4 & 10 \\
\hline Chorthippus parallelus (Zett.) & - & - & 2 & - & - & 2 & 4 & 10 & - & 2 \\
\hline Stethophyma grossum (L.) & - & - & - & - & - & 12 & 20 & 30 & 22 & - \\
\hline Mecostethus alliaceus (Germ.) & - & - & - & - & - & - & - & 4 & 16 & 16 \\
\hline Stauroderus scalaris (F. d. W.) & - & - & - & - & - & - & - & - & - & 2 \\
\hline Chrysochraon dispar (Germ.) & - & - & 4 & - & - & 6 & - & - & 4 & - \\
\hline Euthystira brachyptera (Ocsk.) & - & - & - & 4 & 8 & 2 & - & - & - & - \\
\hline Omocestus viridulus (L.) & - & - & - & - & - & - & 8 & 2 & 8 & 10 \\
\hline Arcyptera fusca (Pall.) & 2 & - & - & 4 & - & - & - & - & - & - \\
\hline Podismopsis poppiusi (Mir.) & - & - & - & - & - & - & - & 8 & - & 6 \\
\hline Stenobothrus lineatus (Panz.) & - & - & - & 4 & - & - & - & - & - & - \\
\hline Суммарное изобилие & 26 & 20 & 22 & 76 & 20 & 100 & 78 & 114 & 118 & 92 \\
\hline
\end{tabular}

Условные обозначения даны в тексте

\section{Материа^ и методы}

Северный Алтай - регион, где за последние годы происходит существенная перестройка характера человеческого влияния. Подвергается модернизации структура сельскохозяйственной деятельности. Это способствует повышению востребованности работ по выявлению особенностей пространственного распределения сообществ прямокрылых данного региона [4]. Худякова Н.Е. в 2005 в ходе своих исследований изучила особенности сезонной динамики и характер распределения сообществ прямокрылых насекомых Северного Алтая [5], но, при этом, изучения структуры и пространственного распределения сообществ прямокрылых в окрестностях с. Ильинка ранее не проводилось.

Исследование биотопического распределения прямокрылых насекомых в с. Ильинка проводилось в августе 2019 года. При учете прямокрылых насекомых использовалась общепринятая методика [7].

\section{Результаты и обсужАения}

В окрестностях с Ильника были изучены группировки прямокрылых насекомых 10 участков, с относительно неоднородным характером растительного покрова.

\section{Сташия № 1.}

Низкогорный

низменно-заболоченный ^уг

Данный участок является переходным от лугового типа растительности к болотному. Проективное покрытие $80 \%$, задернованность около 10\%. Высота травостоя 40-50 см. Почва дерново-глеевая. В растительности преобладают такие виды как: полевица белая, лисохвост луговой, мятлик луговой, овсяница луговая, лопух большой. В небольшом количестве присутствуют бобовые: чина луговая, горошек мышиный, клевер луговой. Кустарниковый ярус представлен ивой сибирской. 
Группировку прямокрылых насекомых этого низменно-заболоченного луга составляют 4 вида, принадлежащих к 2 семействам: Кузнечиковые - Tettigonidae - 1 вид и Саранчовые - Acrididae - 3 вида, относящихся к 2 родам (таблица 1). Преобладающим видом является $-G$. biguttulus, редкими:Arcyptera fusca и Bicolorana bicolor.

\section{Стация № 2. \\ Низкогорный сухоАОАьный разнотравно-з^аковый ^уг}

Участок подвержен влиянию засух и не отличается сравнительно равномерным травостоем в различные года. Проективное покрытие $80 \%$, задернованность не больше 5\%. Высота травостоя около 30 см. Почва слабоподзолистая.

Обильнее всех видов произрастают пырей ползучий, мятлик сибирский, тысячелистник обыкновенный, тмин обыкновенный, земляника зеленая, кровохлебка лекарственная, нивяник обыкновенный, донник лекарственный, мышиный горошек.

На этом участке обнаружено 5 видов прямокрылых насекомых, принадлежащих к 2 семействам: Кузнечиковые - Tettigonidae - 3 вида из двух отрядов и Саранчовые - Acrididae - 2 вида. Преобладающим видом является - Ch. apricarius, редкими: Bicolorana bicolor, Isophya altaica, Conocephalus dorsalis и Ch. fallax (таблица 1).

\section{Сташия № 3.

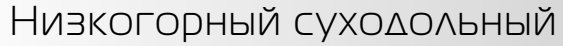

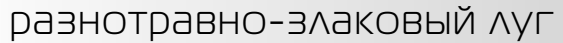

Проективное покрытие 80\%, задернованность не более 5\%. Высота травостоя около 30 см. Преобладают такие виды растений как: тимофеевка луговая, овес обыкновенный, мятлик однолетний, земляника зеленая, тмин обыкновенный, мышиный горошек, герань луговая, василистник малый.

Группировку Orthoptera этой стации составляют 4 вида, относящиеся к семейству Саранчовые-Acrididae и одному отряду (таблица 1). Наиболее встречаемым является вид -G. biguttulus, редким - Ch. parallelus.

\section{Стация № 4. \\ Низкогорный остепненно-сухо ОАьный разнотравно-з^аковый ^уг}

Относительно пологий склон, переходящий в широкуюдолину. Проективное покрытие 75-80\%, задернованность не более 15\%. Высота травостоя 40-50 см. Почва черноземовидная луговая. Местами густота травостоя снижена. Доминирую лугово-степные злаки. Из группы разнотравья отмечаются володушка золотистая, живокость редкоцветковая, герань луговая, кровохлебка лекарственная, бузульник сизый, таволга обыкновенная и змееголовник Рюйша.

На этом участке обнаружено 7 видов прямокрылых насекомых, принадлежащих к семействам: Кузнечиковые-Tettigonidae - 1 вид и Саранчовые-Acrididae6 видов (таблица 1). Преобладающим видом является G. biguttulus, редким - Conocephalus dorsalis.

\section{Стация № 5. \\ Низкогорный сухо ОАьный \\ разнотравно-з^аковый ^уг}

Проективное покрытие $80 \%$, задернованность не более $10 \%$. Высота травостоя около 30 см. Преобладают такие виды растений как: тимофеевка луговая, овес обыкновенныq, мятлик однолетний, лисохвост луговой, волоснец сибирский, земляника зеленая, тмин обыкновенный, мышиный горошек, герань луговая, василистник малый.

Было выявлено 4 вида прямокрылых насекомых, относящихся к 2 семействам: Tettigonidae - 1 вид и Acrididae - 3 вида (таблица 1). Часто встречаемым является вид - E. brachyptera, редким - Gomphocerus rufus.

\section{Сташия № 6. Низкогорный \\ сухо ОАьный овсяницевый ^уг}

Проективное покрытие 85\%, задернованность не более $10 \%$. Почва черноземовидная. Высота травостоя в пределах 40 см. Эдификатор формации овсяница луговая, не образующая густых зарослей. Встречающиеся виды растений: ежа сборная, тимофеевка луговая, овсец пушистый, володушка золотистая, астрагал датский, зопник клубненосный.

На данной стации было собрано 10 видов прямокрылых насекомых, относящихся к 2 семействам: Кузнечиковые - Tettigonidae - 3 вида из 3 отрядов и Саранчовые - Acrididae - 7 видов (таблица 1). Наиболее встречаемый вид - G. biguttulus, редкие: Metrioptera brachyptera, Conocephalus dorsalis, Tessellana vittata, Ch. parallelus и Euthystira brachyptera.

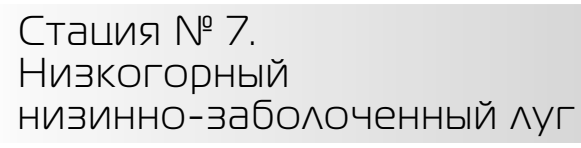

Проективное покрытие 70\%, задернованость около 20\%. Почва дерново-глеевая. Высота травостоя около 
50 см. Кустарниковый ярус представлен ивой сибирской и березой приземистой.

Произрастающие виды: осока двурядная, осока черная, тимофеевка луговая, кровохлебка лекарственная, овсяница красная, мятлик сибирский, лисохвост луговой, жабрица порезниковая.

Группировка прямокрылых насекомых представлена 7 видами, среди которыхпреобладают: Ch. biguttulus и $S$. grossum, редкими являются: G. rufus и Ch. parallelus.

\section{Стация № 8. \\ Низкогорный \\ низинно-заболоченный ^уг}

Проективное покрытие 80\%. Почва лугово-болотная. Высота травостоя в пределах 40 см. Преобладающие виды растений: тимофеевка и полевица тонкая. Произрастающие виды: лисохвост луговой, мятлик болотный, овсяница луговая, клевер розовый, кровохлебка лекарственная.

На данном участке было собрано 9 видов Orthoptera, принадлежащих к 2 семействам: Кузнечиковые Tettigonidae - 1 вид и Саранчовые - Acrididae - 8 видов (таблица 1). Часто встречаемым видом является Stethophyma grossum, редкими: Conocephalus dorsalis и Omocestus viriduius.

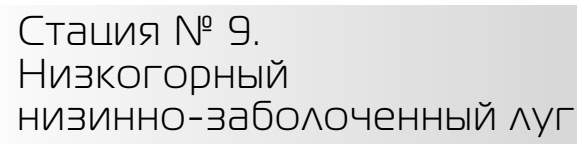

Проективное покрытие 85\%, задернованность $20 \%$. Почва болотно-луговая. Высота травостоя около 30 см. Кустарниковый ярус представлен ивой сибирской. Произрастающие виды растительности: ежа сборная, осока двурядная, ячмень короткоостистый, тимофеевка луговая, кровохлебка лекарственная, овсяница красная, мятлик сибирский, лисохвост луговой.

Прямокрылые насекомые этой стации представлены 8 видами, принадлежащими к 2 семействам: Tettigonidae - 1 вид Acrididae - 7 видов (таблица 1). Часто встречаем вид-G. biguttulus, редким же является вид-Metrioptera brachyptera.

\section{Стация № 10. \\ НИзКОгорныЙ сухОАОАьНО-^есной зАаково-разнотравный $у г г$}

Проективное покрытие 80\%, задернованность $10 \%$. Почва слабоподзолистая. Высота травостоя 3040 см. Произрастающие виды растений: вейник приту- пленный, пырей ползучий, овсец сибирский, ежа сборная, горошек мышиный, володушка золотистая, герань луговая, зопник клубненосный, лапчатка золотистоцветковая, тмин обыкновенный, тысячелистник обыкновенный.

Собранный материал прямокрылых насекомых этого участка представлен 8 видами, относящимися к семейству Саранчовые - Acrididae. Преобладающий вид-Ch. apricarius, редкими являются: Ch. parallelus и Stauroderus scalaris (таблица 1).

Одной из задач данной работы является попытка классификации группировок прямокрылых насекомых окрестностей с. Ильинка. Как было показано выше изученные сообщества не отличаются однородностью и чутко реагируют не только на изменения видового состава растительной ассоциации, но и на различное антропогенное воздействие.

Анализ степени сходства сообществ прямокрылых окрестностей села Ильинка проводился на основе долевого участия в них отдельных видов. Была использована схема, построенная с помощью метода Варда на основе евклидовых расстояний для долей видов в сообществе [8]. Классы выделялись в том случае, если значения евклидовых расстояний были более 80 , а подклассы - при значениях не более 60.

Среди рассмотренных группировок прямокрылых насекомых можно выделить 2 класса (рисунок 1). К первому классу относятся лишь две группировки низкогорного суходольного разнотравно-злакового луга расположенные у южного подножья и на северном склоне г. Межалик. Близость описываемых группировок прямокрылых связана с относительно однородным растительным покровом, структурой почвы и географическим расположением. Также эти группировки бедны по видовому составу, доминирует лиственно-лесной Ch. apricarius. Не смотря на общность местоположения, описанные группировки невозможно назвать единым целым. Потому что в группировке суходольного разнотравно-злакового луга, расположенный на северном склоне г. Межалик присутствуют такие виды как: Roeseliana roeselii, Gomphocerus rufus и Euthystira brachyptera не характерные для суходольного разнотравно-злакового луга, расположенный у южного подножья г. Межалик. Отсутствие этих видов в группировке суходольного разнотравно-злакового луга, расположенный у южного подножья г. Межалик связано именно с тем, что данный луг регулярно подвергается антропогенному воздействию (сенокосное угодье).

Все остальные группировки были отнесены ко второму классу, однако мы не можем говорить о его однород- 


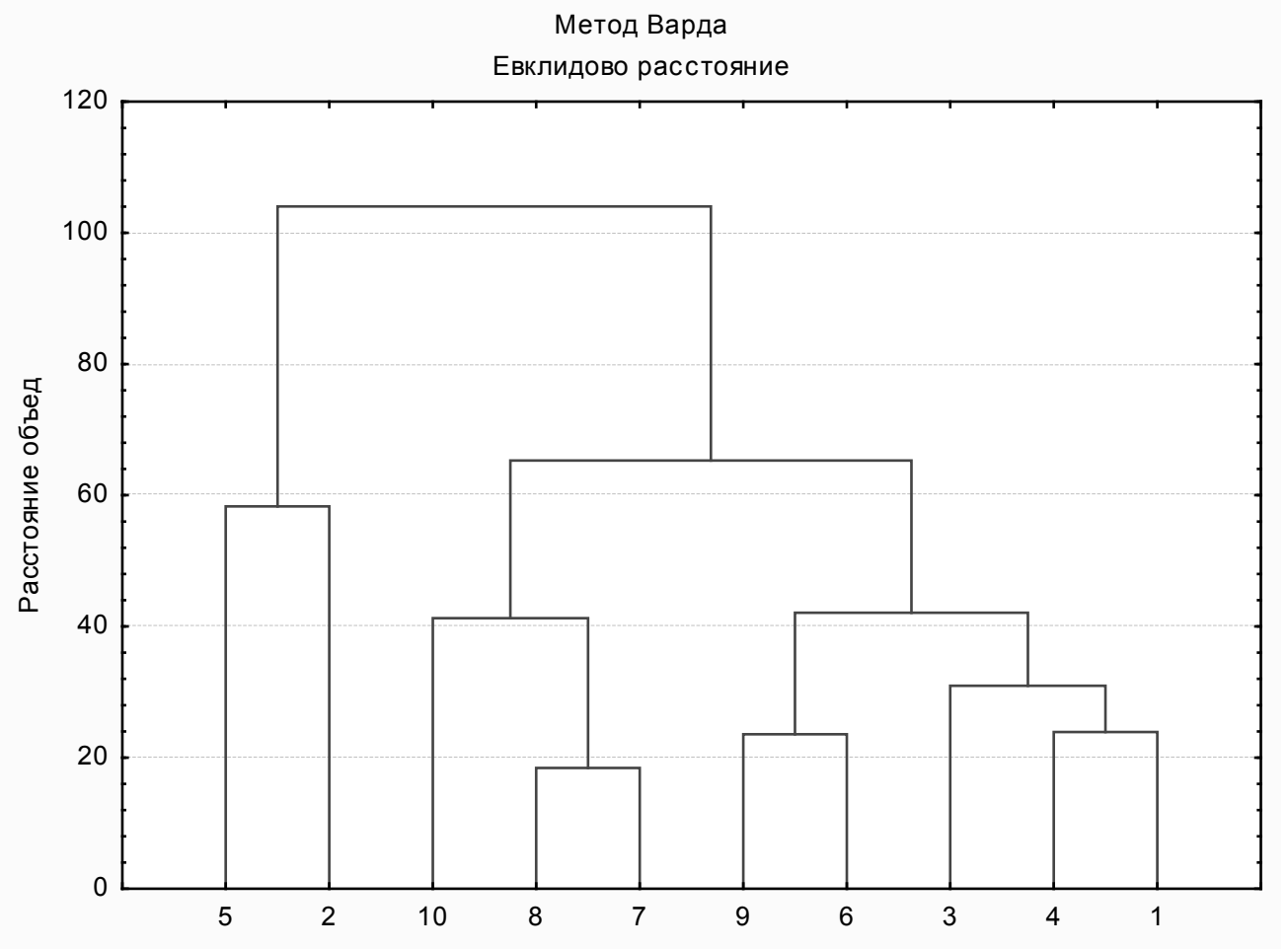

Рис. 1. Дендрограмма сходства для сообществ прямокрылых насекомых окрестностей с. Ильинка Условные обозначения даны в тексте

ности (рисунок 1), имеет смысл, в рамках данного класса выделить два подкласса.

К первому из них относятся низинно-заболоченный луг, расположенный вблизи «курятника», низинно-заболоченный луг, расположенный на берегу р. Песчанная и суходольно-лесной злаково-разнотравный луг, расположенный в Широком логу. Объединение на первый взгляд не похожих группировок прямокрылых в один подкласс связано с значительной долей участия в их структуре следующих видов: G. biguttulus, Ch. apricarius (как правило доминируют), Ch. fallax и Omocestus viriduius (редко встречающиеся). Наиболее близки между собой сообщества низинно-заболоченных лугов с разной высотой растительного покрова. В них по мимо указанных четырех видов значительную роль в сообществе играет большая болотная кобылка (Stethophyma grossum), являющаяся субдоминантом. К ним тяготеет и сообщество суходольного луга за счет присутствия в его составе зеленой болотной кобылки (Mecostethus alliaceus).

Группировки Orthoptera составляющие второй подкласс менее однородны (рисунок 2) и их можно объединить в две совокупности (при значении евклидовых расстояний свыше 50). К первой из них относим суходольный овсяницевый луг, расположенный у подножья г. Школьная и низинно-заболоченный луг, расположенный на берегу р. Песчанная в Широком логу. Они имеют довольно сходный видовой состав из 8 (9) видов, составляющих описываемые группировки - 6 являются общими. Доминирующим видом в обоих случаях является $G$. biguttulus

Вторую совокупность составляют ортоптероидные группировки трех стаций: низменно-заболоченный луг, расположенный вблизи ручья Карасук, суходольный разнотравно-злаковый луг, расположенный на северо-западной вершине г. Межалик и остепненно-суходольный разнотравно-злаковый луг, расположенный вблизи Лисьего лога. Несмотря на различный видовой состав, их объединяет то, что в структуре данных сообществ явно доминируют два полизональных вида: $G$. biguttulus и Ch. apricarius.

\section{Зак^ючение}

Таким образом в описанных нами десяти сообществах прямокрылых насекомых было обнаружено 20 видов распределение которых по стациям было не равномерно некоторые виды такие как полизональные Ch. biguttulus и Ch. apricarius распространены практически повсеместно. В то время как Stethophyma grossum и Omocestus viriduius приурочены к низин- 
но-заболоченным лугам. Имеют место быть и единично отмеченные виды, так Tessellana vittata и Roeseliana roeselii обнаружены на суходольном овсяницевым лугу, расположенном у подножья г.Школьная, Isophya altaica на сууходольном разнотравно-злаковом лугу, расположенный у южного подножья г. Межалик, Stauroderus scalaris на суходольно-лесном злаково-разнотравном лугу, расположенный в Широком логу, Stenobothrus lineatus на остепненно-сухо- дольном разнотравно-злаковом лугу, расположенный вблизи Лисьего лога, своим присутствие делают эти местообитания уникальными.

Используя метод Варда, нами было выведено и описано 2 класса с тремя подклассами. Основными признаками для классификации группировок прямокрылых служили: биологическое разнообразие, антропогенная нагрузка и высота растительного покрова.

\section{ЛИТЕРАТУРА}

1. Samways M.I. Orthoptera and landscape changes. / M.I. Samways, M.G. Sergeev // The bionomics of grasshoppers, katydids and their kin. - Oxon et al.: CAB International, 1997.- 147-162 c.

2. Sergeev M.G. Conservation of Orthopteran biological diversity relative to landscape change in temperate Eurasia / M.G. Sergeev // Journal of Insect conservation 1998. — № 2-247-252 C.

3. Суртаева 0.А. Материалы по фауне прямокрылых насекомых в окрестностях с. Бирюля / О.А. Суртаева, Н.Е. Худякова // Материалы IV международной конференции.- Горно-Алтайск, 2016. - 140-173 с.

4. Uvarov B.P. Grasshoppers and Locusts / B.P. Uvarov // A Handbook of General Acridology — London: Center for Overseas Pest Research, 1977. — vol. 5-384-391 c.

5. Худякова Н.Е. Прямокрылые насекомые (Orthoptera) Северного Алтая (фауна, сезонная динамика и характер распределения сообществ) / Н.Е. Худякова. - Новосибирск: 2005.- 24 с.

6. Худякова Н.Е. Оценка влияния рекреационного природопользования на население прямокрылых насекомых (Orthoptera) Катунского рекреационного района Республики Алтай/ Н.Е. Худякова, П.Ю. Малков, Т.С. Худякова // научное обозрение. Биологические науки — № 6- декабрь, 2016 - с. 76-80

7. Правдин Ф.Н. Некоторые принципы и приемы исследования смешанных популяций нестадных саранчовых в разных ландшафтных условиях/ Ф.Н. Правдин, И.Г. Крицкая, М.Е. Черняховский //Фауна и экология животных. М.,1972.- С. 3-16

8. Песенко Ю.А. Принципы и методы количественного анализа в фаунистических исследованиях /Ю.А. Песенко — М.: Наука, 1982-287 с.

\footnotetext{
○ Конокпоева Любовь Александровна ( konokpoeva92@gmail.com ), Худякова Надежда Ефремовна ( Nch752@bk.ru ), Сафонова Оксана Владимировна ( oksvarias@mail.ru ), Шмакова Наталья Юрьевна ( Nataliashmakova1998@gmail.com ),

Петунина Светлана Сергеевна ( petunina-sveta@mail.ru ).
}

Журнал «Современная наука: актуальные проблемы теории и практики»

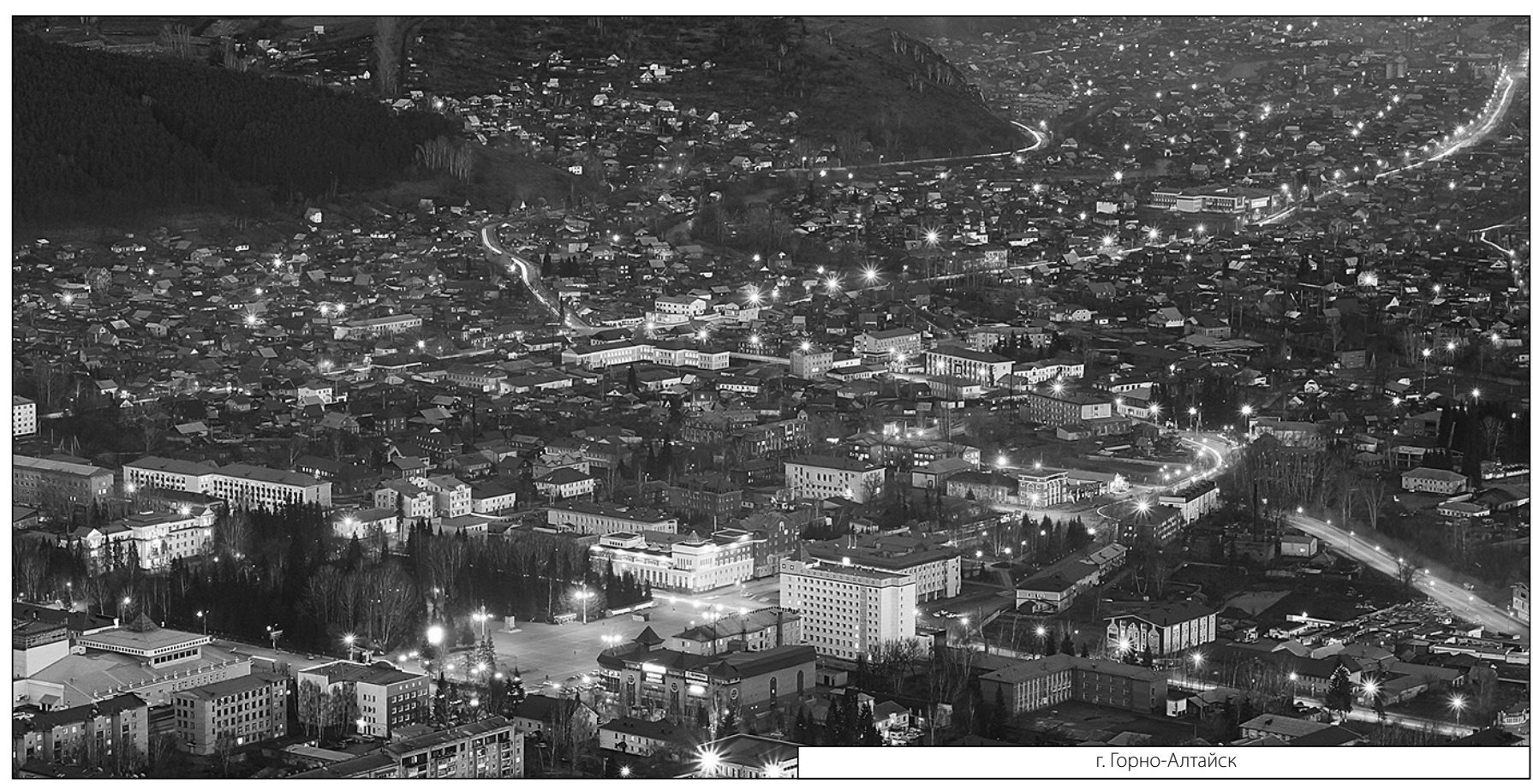

